\title{
Scheinbar anomale Zersetzungen durch
}

Kohiensäure ;

von Ar. Mohr.

(Eingelanfen den 3. December 1876.)

Die Kohlensâure gilt für eine der schwächsten Säuren, welche durch jede andere ausgetrieben werden könnte. Doch giebt es auch Fälle, wo die Kohlensäure weit stärkere Säuren, wie Phosphorsäure, Essigsăure, Chromsäure und andere zu verdrängen im Stande ist. Die Erforschung solcher Fälle ist der Gegenstend des Folgenden.

Die Konlensäure wurde in einem grofsen Kip p'schen Apparate aus Marmor und verdünnter Salzsäure entwickelt und einmal durch eine Waschflasche mit doppelt-kohlensaurem Kali hindurchgeleitet. Die Absorption fand in einem Kölbchen statt von ungefähr $150 \mathrm{CC}$. Inhalt. Dieses war mit einem doppelt durchbohrten Kautschukstopfen versehen, dessen eine Oeffnung die zuleitende Glasröhre aufnahm, während die andere durch eine Glasröhre mit Kautschukrohr und Quetschhahn versehen war. Durch diese konnte man die in der Absorptionsflasche enthaltene Luft herauslassen und dann nach Schlufs des Quetschhahns die Flüssigkeit unter dem Drucke reiner Kohlensäure stehen lassen. Beim Schütteln der mit langer Kautschukröhre versehenen Absorptionsflasche konnte man an der Waschflasche sehen, ob noch Gas aufyenommen wurde.

1. Essigsaurer Baryt. - $10 \mathrm{Grm}$. wurden in Wasser gelöst, filtrirt und auf $100 \mathrm{CC}$. verdünnt in die Absorptionsflasche gebracht. Es entstand sehr bald eine Trübung der Flüssigkeit, dann unter fortwährender Absorption ein reich- 
licher Niederschlag. Als keine Absorption mebr statt fand, wurde abgenommen. Die Fuassigkeit röthete blaues Lackmuspapier sehr stark. Der durch Auswaschen gereinigte kohlensaure Baryt wog geglaht 0,887 Grm. Das klare Filtrat warde erhitzt, um die Kohlensăure su vertreiben und dann mit Barytwasser und Lackmus titrimetrisch gemessen. Das Barytwasser hatte den Titer : $\times 0,341=$ Normal. Es wurden $26,2 \mathrm{CC}$. Barytwasser verbraucht $=8,9342 \mathrm{CC}$. Nornal und diese mit 0,060 multiplicirt zeigen $0,539 \mathrm{Grm}$. Bssigsăurehydrat an, welche in Freiheit gesetzt waren. Aus dem kohlensauren Baryt berechnet sich das Essigsäurehydrat $(78,5: 60=$ 0,887 : x) zu 0,678 Grm.

Durch das lëngere Kochen, um die Kohlensãure auszutreiben, war etwas Essigsáure verflüchtigt worden.

Wir haben also hier den ganz bestimuten Fall, dafs Kohlensăure Essigsăure ausgetrieben hat, und wir finden genügenden Grund dazu in der Unlöslichkeit und Cohãsion des kohlensauren Baryts.

Bssigsaurer Kalk und Strontium gaben keine Niederschläge.

2. Essigsaures Zinkoxyd. - $10 \mathrm{Grm}$. zu $100 \mathrm{CC}$. gelöst. Es bildete sich ein krystallinischer Niederschlag, welcher ausgewaschen 9,4 CC. kohlensaures Gas $=0,018 \mathrm{Grm}$. ergab. Die filtrirte Flüssigkeit trübte sich beim Erhitzen durch Entweichen von Kohlensäure, wodurch also doppelt-kohlensaures Zinkoxyd zersetzt wurde, klärte sich aber bei fernerem Kochen wieder auf, indem die freie Bssigsāure das kohlensaure Zinkoxy' wieder löste.

3. Bleizucker. - $10 \mathrm{Grm}$. zu $100 \mathrm{CC}$. gelöst und filtrirt Beim Einleiten ron Kohlensäure zeigte sich sehr bald eine Trübung und allmälig bildete sich ein sehr reichlicher Niederschlag von tohlensaurem Bleioxyd. Dasselbe abgewaschen und auf einem Filtrum mit gleich schwerem Gegenfiltrum als 
Tara gewrogen betrug $4,715 \mathrm{Grm}$. Die Kohlensäure bestimmt wog 0,785 Grm.; berechnet 0,776 Grm. Die klar filtrirte Flüssigkeit reagirte stark sauer. Es wurde die Kohlensáure weggekocht und die Sãure mit Barytwasser gemessen. Es wurden 113,6 CC. des obigen Barytwassers verbraucht = 38,7376 CC. Normal, und diese mit 0,051 multiplicirt geben 1,9756 Grm. wasserleere Essigsäure. Die angewandten $10 \mathrm{Grm}$. Bleizucker enthalten $\frac{51 \times 10}{190}=2,684$ Grm. wasserleere Rssigsŭure; es waren also $\frac{1,9756 \times 100}{2,684}$ oder 73,60 p C. von dem Bleizucker durch die Kohlensāure zersetzt worden. Bei sehr niedriger Temperatur würde sicher noch mehr zersetzt worden sein. Es ist eine bekannto Erfahrung, dafs Bleizucker selbst mit destillirtem Wasser niemals eine vollkommen klare Lösung giebt. Trockener Bleizucker mit kohlensanrem Gase geschüttelt absorbirte nichts, wie man an der Waschflasche ersehen konnte. Wurde Wasser hinzugegeben, so entstand sogleich eine trübe Lösung und die Absorption ging wieder rasch vor sich. Hierbei wurde die Beobachtung gemacht, dafs die Blasen der Kohlensäure anfänglich rasch platzten; als aber der Niederschlag bedeutender wurde, blieben die Blasen stehen, füllten das Gefäfs und drohten überzusteigen. Hs $_{\text {s }}$ ist diefs eine Cohäsionserscheinung, die sich leicht erklärt. Wasser hat zu festen Körpern, die keine Fette sind, eine grörsere Adhũsion als zu sich selbst, weshalb solche Körper benetzt aus dem Wasser herausgezogen werden. Ist nun eine Flússigkeit mit festen Körpern gemengt, so entsteht dadurch eine grörsere Cohäsion, worauf das Blasenbilden beruht. Dieselbe Erscheinung tritt ein, wenn man Kohlensäure durch Barytwasser auffängt und bestimmt. Anfangs, wo noch viel atmosphärische Luft durchgeht, platzen die Blasen leicht, sobald aber das Barytwasser milchweifs geworden ist, so steigen 
die Blasen auf und platzen erst aach längerer Zeit. Batwickelt man Chlorgas aus feinem Braunsteinpulver, so ateigt die Masse ebenfalls leicht über. Der entgegengesetzte Fall ist der, wo Fette auf der Flüssigkeit schwimmen. Das Wasser hat zu Fett weniger Adhāsion als zu sich selbst. Wird ein Tröpfchen Paraffin oder Talg auf eine Blase gehoben, so mufs die Blase platzen, weil sich das Wasser von dem fetten Körper wegzieht und durch das entstehende Loch entweicht die Luft und die Blase fällt zasammen. Wie wenig Parafta dazu gehort, eine grofse Oberfläche ruhig kochend zu machen, erkennt man aus der irisirenden Schicht, welche flüssige Fette auf einer nassen Oberfläche bilden. Das geschmolzene Paraffin bedeckt in gleicher Weise die ganze Oberflăche.

Um wieder auf unseren Gegenstand zuräckzukommen, so haben die bisher vorgefahrten Beispiele, wobei unlösliche kohlensaure Verbindungen ausgeschieden wurden, in der entstehenden Cohäsion der neuen Verbindung eine genuggende Erklärung gefunden.

Bs giebt aber auch Fälle, wo nichts ausgeschieden wird und dennoch eine Zersetzung erfolgt.

4. Einfach-chromsaures Kali. - 5 Grm. wurden $2 u$ 100 CC. gelöst. Die Absorption ging stark vor sich, die Farbe der Flüssigkeit verdunkelte sich, doch nicht ganz so stark, als wenn Bichronat vorläge. Nachdem die Absorption vollendet war, wurde der Kohlensäureapparat abgelōst, die Flasche mit einem Blasebalg ausgeblasen, um das nicht absorbirte Gas zu entfernen und dann die absorbirte Kohlensäure durch Kochen ausgetrieben und in 3 vorgelegten Flaschen mit Chlorbaryum-Ammoniak aufgefangen. Ein Strom kohlensäurefreier Luft (durch eine Kalk-Glaubersalzröhre) wurde durch die 4 Flaschen durchgesaugt, die 3 Chlorbaryumflaschen im Wasserbade erhitzt und nach dem Erkalten der kohlensaure Baryt gesammelt und gewogen. Br wog 2,675 Grm. Die 
ansgekochte Chromsalzlösung gab mit Chlorcalcium keinen Niederschlag und entwickelte mit Salzsŭure keine Kohlensäure. Es war also alle Kohlensáure durch das Kochen wieder ausgetrieben worden.

Die $5 \mathrm{Grm}$. chromsaures Kali enthalten 2,420 Grm. Kali und diese verlangen Kohlensăure 1,130 Grm.

Die 2,675 Grm. kohlensaurer Paryt $(\times 0,223)$ enthalten 0,596 Grm. Kohlensäure; man kann also annehmen, dafs $\frac{0,596 \times 100}{1,130}=52,7 \mathrm{pC}$. des Kalis an Kohlensăure getreten und eine entsprechende Meage doppelt-chromsaures Kali gebildet worden sei, wofür die Verdunkelung der Farbe spricht; oder man kann annehmen, dafs sich doppelt-kohlensaures Kali neben doppelt-chromsaurem Kali und neben absorbirter Kohlensāure gebildet babe. Nehmen wir den Absorptionscoëfficient für die vorliegenden Fälle gleich dem des reinen Wassers, was sicher die ungünstigste Annahıe ist, so betrăgt derselbe, da die Versuche bei Zimmertemperatur gemacht wurden, bei $19,1^{\circ} \mathrm{C}$. $)$ 0,8963. Die $100 \mathrm{CC}$. Flüssigkeit konnten also $89,63 \mathrm{CC}$. Kohlensăure absorbirt halten, $1 \mathrm{CC}$. Kohlensâure bei $19^{\circ} \mathrm{C}$. und 760 MM. Bar. wiegt nach Dietrich's**) Tabelle 0,001799 Grm.; die 89,63 CC. wiegen also 0,161 Grm.; ziehen wir diese als möglicherweise absorbift von den $0,596 \mathrm{Grm}$. ab, so bleiben $0,485 \mathrm{Grm}$. Kohlensãure als von Kali gebunden abrig, und nehmen wir Bicarbonat an, so nehmen die 0,485 Grm. Kali $0,435 \mathrm{Grm}$. Kohlensäure auf, um damit 0,900 Grm. doppelt-kohlensaures Kali zu bilden. Der Rest ist dann einfach- und doppelt-chromsaures Kali. Das letztgenannte Salz ist kein saures, sondern höchstens ein neutrales Salz, da es

-) Bunsen, gasometrische Methoden, S. 162.

-) Preseniu a, Zeitwohrift f. anal. Chemie, 4, 143. 
Jodkalium nicht zersetzt; in diesem Sinne ist das einfachchromsaure Kali ein basisches Salz und deshalb die Absorption der Kohlensâure erklărlich.

5. Borax. - 5 Grm. zu 100 CC. gelöst. Die Lösung nahm sehr viel Kohlensãure auf, blieb aber natürlich klar. Die Kohlensãure wurde durch langes Kochen ausgetrieben. Die abgekochte Flüssigkeit gab mit verdünntem Chlorcalcium einen starken Niederschlag und entwickelte init Salzsăure kohlensaures Gas. Es war also Borsäure ausgeschieden und durch das Kochen nicht wieder ganz in Besitz des Natrons getreten, so dafs kohlensaures Natron neben freier Borsăure vorlag. Der aus den Chlorbaryum - Ammoniakflaschen gewonnene koblensaure Baryt wog 1,995 Grm. $=0,445 \mathrm{Grm}$. Kohlensăure, und ziehen wir davon die möglich absorbirte Kohlensãure mit 0,161 Grm. ab, so bleiben 0,284 Grm. Kohlensăure welche zersetzend auf den Borax eingewirkt haben.

Kieselfeuchtigkeit und Wasserglas werden durch Kohlensãure bis zum Gelatiniren zersetzt. Es wurden darüber keine Versuche gemacht, da diese Flässigkeiten schon in ihren Flaschen Kohlensäure anziehen.

6. Phosphorsaures Natron. - $10 \mathrm{Grm} .2 \mathrm{zu} 100 \mathrm{CC}$. gelōst. Reichliche Absorption. Die ausgekochte Kohlensăure gab 2,811 Grm. kohlens. Baryt $(\times 0,223)=0,627 \mathrm{Grm}$. Kohlensãure. Davon ab die möglich absorbirten 0,161 Grm. lassen 0,466 Grm. gebunden an Natron, so dafs hier Kohlensăure die Phosphorsāure verdrāngt bat. Die ausgekochte Flüssigkeit enthielt keine Kohlensäure mehr, brauste nicht mit Salzsāure und fältte Silbersalze gelb. Phosphorsaures Natron reagirt alkalisch; es färbt Cochenilletinctur violett, und man kann darin das Natron mit Salzsãure gustitriren, als wenn gar keine Phosphorsaure vorhanden wäre.

7. Phosphorsaures Natron-Ammoniak (Sal microcosmicum). - 10 Grm. 2u 100 CC. gelöst; die Absorption 
geschah rasch und reichlioh. Die durch Kochen ausgetriebene Kohlensāure gab 2,831 Grm. Kohlensauren Baryt $=0,631 \mathrm{Grm}$. Kohlensäure. Es waren also hier nach Abzug der absorbirten Kohlensăure 0,470 Grm. $\mathrm{CO}_{2}$ gebunden und hatten eine entsprechende Menge Phosphorsäure depossedirt.

8. Essigsaure Natron. - 10 Grm. zu 100 CC. gelöst. Die durch Kochen vertriebene Kohlensäure erzeugte 1,080 Grm. kohlensauren Baryt $=0,240 \mathrm{Grm}$. Kohlensëure. Davon die möglich absorbirte Kohlensåure mit 0,161 Grm. abgezogen lassen 0,079 Grm. Kohlensäure als gebunden und als neben der in Freiheit gesetzten Essigsäure vorhanden erkennen. Da sich hier nichts ausscheiden konnte, so beträgt die Menge der aufgenommenen Kohlensäure weniger, als in jenen Fällen von essigsaurem Baryt und Bleioxyd.

9. Seignettesalz. - Nicht gewogene Menge. Nach einiger Zeit trübte sich die Flüssigkeit und es schied sich Weinstein aus, der mit $W$ eingeist abgewaschen und init Baryt titrirt sich zu 0,2564 Grm. herausstellte. Auch hier wirkte die entstehende Cohäsion des Weinsteins auf die fortschreitende Zersetzung.

Aus den mitgetheilten Fällen ist ersichtlich, dafs Kohlensåure unter Verhältnissen im Stande ist, Essigsäure, Chromsäure, Phosphorsäure, Borsäure, Kieselsäure, Weinsäure aus dem Besitz von Basen zu verdrängen und sich an ihre Stelle zu setzen und da Kohlensäure eine der schwächsten Säuren ist, so kann man wohl allgemein voraussetzen, dafs jede zu einem Salze hinzukommende andere Säure einen Theil desselben zersetzen und sich in Besitz eines Theiles der Base setzen werde, selbst wenn kein Niederschlag entsteht. Wird Kohlensäure absorbirt, so wird Wärme frei und die Sumıne der freiwerdenden Wärme ist, aufser von der Menge der Kohlensäure, abhängig von dem neuen Cohäsionszustande der Kohlensäure, d. h. von ihrer Flüchtigkeit in der neuen Verbindung. 
Kohlensăure von Wasser absorbirt entwickelt weniger Warme als von einfuch-kohlensaurem Natron absorbirt; mit diesem weniger als von Kalkhydrat; mit diesem weniger als von Barythydrat. Die freiwerdende Wărme ist das Mafs der molecularen Bewegung, welche die Kohlensăure in jedem einzelnen Falle ausgiebt, und da die Kohlensăure im kohlensauren Baryt weniger flüchtig ist, als im kohlensuuren Kalk, so mufs sie im ersten Palle mehr Wărme ausgeben. Umgekehrt mufs die Kohlensăure, wenn sie entwickelt wird, wieder freie Wärme aufnehmen, um in den Gaszustand überzutreten, und wenn diese nioht vorhanden ist, so findet die Zersetzung nicht slatt. So fand $L$ a ndolt, dafs Salzsāure den kohlensauren Kalk bei $-20^{\circ} \mathrm{C}$. nicht angreift und zersetzt, wohl aber noch kohlensaures Natron. Im ersten Falle war noch dio Cohâsion zu überwinden, worauf immer ein Theil lebendige Kraft verwendet werden mufs. Es ist auch eine Temperatur denkbar, wobei die Salzsauure auch das kohlensaure Natron oder Kali nicht mehr zersetzt. Dafs verdünnte Säuren schwãcher wirken als concentrirte, erklärt sich dadurch. dafs das verdünnende Wasser an der freiwerdenden Warme Theil nimmt. Salzsäure zersetzt bei gewöhnlicher Temperatur den gefällten kohlensauren Kalk, Strontian, Baryt, äber schon viel schwächer Kalkspath, Arragonit, Strontianit und Witherit; dagegen greift sie krystallisirten Eisenspath, Zinkspath, Manganspath, Weifsbleierz ohne Erwärmung nur unbedeutend an. Wird aber die für den Gaszustand der Kohlensäure fehlende Wärme von aufsen zugeführt, so geht die Zersetzung bis zu Ende vor sich.

Bohrsàure und kohlensaures Natron entwickeln kein Gas; darch Kochen wird aber reichlich Kohlensäure entwickelt und durch vorgelegtes Barytwasser nachgewiesen; umgekehrt sahep wir oben die Kohlensäure Borsăure ausscheiden, aber bei niederer Temperatur; dasselbe gilt för die anderen vorge- 
führten Palle. Yon diesen reciproken Processen ist der wichtigste das gegenseitige Verhalten von Kohlensăure und Kieselsăure, welches bei dem Bau der Gebirge die grörste Bedeutung hat. Kohlensăure zersetzt bei anhaltender Einwirkung alle natürlichen Sillcate. Der Feldspath, ein Trisilicat von Kali und Thonerde, welches wir im gepulverten Zustande nicht durch Salzsāure oder Schwefelsăure aufschliefsen können, wird in der Natur im festen krystallinischen Zustande in Kaolin verwandelt, der noch auf dem darunter liegenden Granit aufsitzt. In gleicher Weise werden Basalt, Diorit, Dolerit und ähnliche Felsarten in loco in plastischen Thon verwandelt, und die dicht daneben liegenden Braunkohlenlager zeigen dafs Kohlensäure das zersetzende Agens war. Umgekehrt dringen Kieselerde haltende Infiltrationen in Kalkstein, Thonschiefer, Sandstein ein, und verwandeln diese in Basalt, Dolerit, Gneifs, Granit je nuch der Natur der aufgelösten Stoffe. Bei Kalkgebirgen mufs sich die Kohlensăure gasförmig entwickeln, wozu die nach unten zunehmende Temperatur, der Brde die Wärme hergiebt. Bei Daubitz in Böhmen, unweit Herrenhut, stöfst ein in Säulen anstehender Basalt an einen gelben Kalkstein und auf der Zwischenstufe finden sich alle Mengungen von Basalt und Kalk. Die Farbe des Kalksteines geht allmälig durch Grau in Schwarz über und er kann dann nicht mehr zu Aetzkalk gebrannt werden, weil er verglast und sich nachher nicht mehr mit

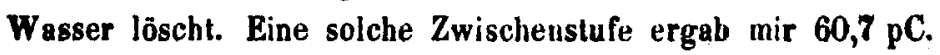
kohlensauren Kalk und schon 1,104 pC. Magneteisen. Näher am Basalt waren nur mehr $50,167 \mathrm{pC}$. kohlensaurer Kalk vorhanden. In unseren siebengebirgischen Basalten ist nicht ein Kubikzoll zu schlagen, der nicht kohlensaures Eisenoxydul und kohlensauren Kalk enthielte, welche Bestandtheile jede Annahme eines feuerflüssigen Zustandes abweisen. Wir können ubrigens die beiden ungekehrten Processe künstlich nachahmen. Wasserglas wird durch Kohlensäure vollständig zer- 
setzt und wenn man gefallte und geglühte Kieselsäure mit einfach-kohlensaurem Natron kocht, 80 geht reichlich Koblenslure über. Es ist bekannt, dafs man analytisch die ausgoschicdene Kieselerde durch Kochen mit kohlensaurem Natron auf ihre Reinheit prüft, und dafs wenn sie sich darin lōst, nothwendig die Kohlensăure ausgeschieden sein muls. Ebenso wurde analytische Kieselerde mit gefälltem kohlensaurem Kalk gekocht und dabei reichliche Mengen Kohlensaure in Barytwasser aufgefangen. Was wir hier durch Siedhitzo erreichen, erzwingt die Natur durch die Lãnge der Dauer. Eine Reiho solcher Vorgänge kommen in der Natur vor, welche wir in unseren Laboratorien mit den stärksten Agentien nicht nachahmen kōnnen. Schwefelkies wird von Salzsäure nicht angegriffen; in der Natur wird er durch Kohlensäure und Sauerstoff in Brauneisenstein umgeselzt. Bergkrystall löst sich weder in Flufssãure noch atzendem Alkali. In der Natur finden wir angenagle Bergkrystalle, die mit einem wasserholtigen Chloril durchzogen sind. Von den unlöslichsten Stofien, wio Plufsspath, Schwerspath u. a. finden sich Pseudomorphosen, wo also diese Körper durch Wasser mūssen weggeführt worden sein. Für Manganhyperoxyd kennen wir kein Lösungsmittel und dennoch findet sich der Pyrolusit in schönen Krystallen ausgebildet. Hier bewirkt die Zeit, was die stärksten Affinitâten nicht vermögen. 